\title{
A grande fronteira: Amazônia e a formação do sistema agroextrativista global
}

\author{
Gabriel Domingues ${ }^{1}$ \\ https://orcid.org/0000-0002-4934-6534
}

\author{
Sérgio Sauer, \\ https://orcid.org/0000-0002-2014-3215
}

${ }^{1}$ Universidade de Brasília, Programa de Pós-Graduação em Desenvolvimento Sustentável, Brasília, DF, Brasil ${ }^{2}$ Universidade de Brasília, Faculdade UnB Planaltina, Programa de Pós-Graduação em Meio Ambiente e Desenvolvimento Rural, Brasília, DF, Brasil

\begin{abstract}
A grande fronteira: Amazônia e a formação do sistema extrativo agrário global
Resumo: Este artigo situa a Amazônia no processo histórico de formação da fronteira extrativa agrária, a partir da dinâmica de apropriação da terra e do território, extração de recursos e exploração do trabalho, que se inicia no período colonial, moldando o desenvolvimento do capitalismo no Brasil. A análise foi realizada tendo três eixos principais: i) a formação da fronteira extrativa agrária e a inserção da Amazônia nesse processo histórico; ii) a natureza extrativa da economia neoliberal, a partir do conceito de acumulação por espoliação; iii) a compreensão do subdesenvolvimento da Amazônia, a partir da ruptura dos sistemas ecológicos, sociais e produtivos, provocada pelos sucessivos ciclos extrativos que marcaram a inserção da região na economia global. Tais processos abriram caminho para a apropriação generalizada dos recursos e espoliação das comunidades amazônicas, atendendo às demandas de acumulação do capital extrativo agrário, em um contexto histórico de radicalização do neoliberalismo.
\end{abstract}

Palavras-chave: Capital extrativo agrário; Neoliberalismo; Fronteira extrativa agrária; Amazônia.

\section{The great frontier: Amazon and the formation of the global agrarian extractive system}

Abstract: This article situates the Amazon in the historical process of formation of the agrarian extractive frontier, based on the dynamics of the appropriation of land and territory, resource extraction and labor exploitation, which began in the colonial period, shaping the capitalist development in Brazil. The analysis was done considering three main aspects: i) the formation of the agrarian extractive frontier and the insertion of the Amazon in this historical process; ii) the extractive nature of neoliberal economy, based on the concept of accumulation by dispossession; iii) the understanding of the Amazon's underdevelopment, based on the rupture of ecological, social and productive systems, caused by successive extractive cycles that marked the region's insertion in the global economy. Such processes opened the Amazon for a wide spreading appropriation of resources and the dispossession of communities, fulfilling demands for the accumulation of agrarian extractive capital, in a historical context of radicalization of neoliberalism.

Keywords: Agrarian extractive capital; Extractive neoliberalism; Extractive agrarian frontier; Amazon.

Recebido em 25.02.2021. Aprovado em 15.05.2021. Revisado em 10.07.2021.

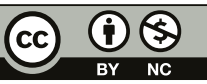

Este é um artigo publicado em acesso aberto (Open Access) sob a licença Creative Commons Attribution NonCommercial, que permite uso, distribuição e reprodução em qualquer meio, sem restrições desde que sem fins comerciais e que o trabalho original seja corretamente citado. 


\section{Introdução}

Diante do cenário atual de ascensão da extrema direita no poder, observa-se no Brasil um desmonte gradual e contínuo das políticas agrárias e ambientais, em resposta à pressão do capital extrativo agrário pela derrubada das últimas barreiras que ainda restam à sua expansão. Reacende-se, assim, o debate acerca do modelo de desenvolvimento pensado para a Amazônia e das causas de a região ser constantemente reduzida à condição de fornecedora de recursos para o atendimento de interesses externos, em suma, à condição de uma fronteira extrativa agrária.

Deve-se entender, primeiramente, que a Amazônia é colocada na condição de fronteira extrativa agrária a partir de três processos distintos e complementares: 1) como fornecedora de produtos florestais, no contexto das relações colônia-metrópole; 2) sendo integrada à economia brasileira, primeiramente a partir da exportação da borracha e, posteriormente, como fornecedora de recursos para a expansão da agricultura mecanizada, da exploração mineral e da geração de hidro energia; e 3) como fonte de ativos para a acumulação do capital extrativo agrário, em um contexto de radicalização da doutrina neoliberal.

Este artigo situa a Amazônia no processo histórico de formação da fronteira extrativa agrária, a partir da dinâmica de apropriação do território, extração de recursos e exploração do trabalho. Tal dinâmica se inicia no período colonial, moldando a forma com que se dará o desenvolvimento do capitalismo no Brasil.

O aprofundamento da racionalidade neoliberal nas últimas décadas vem propiciando a estruturação de um sistema econômico global de características extrativas. No caso da Amazônia, tal processo se caracteriza pela aceleração da ruptura ecológica, social e institucional que, ao longo de sucessivos ciclos extrativas, tem levado ao subdesenvolvimento da região e à exaustão dos seus bens naturais.

Além desta introdução, o artigo está dividido em outras três partes. A primeira parte discute a formação da fronteira extrativa agrária no Brasil, bem como a inserção da Amazônia nesse processo histórico. Observase o papel relegado ao Brasil de exportador de bens primários, herdado do período colonial, e à Amazônia de fronteira agrícola, mineral e energética, com o aprofundamento da divisão territorial do trabalho e das trocas entre a agricultura e a indústria (MOREIRA, 2011) na segunda metade do século XX.

A segunda parte discute, tendo em vista o conceito de acumulação por espoliação de Harvey (2003), a natureza extrativa assumida pela economia neoliberal, em especial a partir do final do século XX. Ressalta o estabelecimento do Consenso das Commodities (SVAMPA, 2014) na América Latina nas últimas décadas e analisa, com base na crise financeira de 2008, a dinâmica de apropriação global de terras, com o reforço das narrativas voltadas às crises alimentar, ambiental, energética e climática (SAUER; BORRAS, 2016; SAFRANSKY; WOLFORD, 2011).

Tendo como base as contribuições de Bunker $(1984$, 1988) e Becker (2009a, 2009b), a terceira parte discute de que forma os sucessivos ciclos extrativos provocaram rupturas dos sistemas ecológicos, sociais e produtivos na Amazônia. Rupturas essas que têm reforçado o padrão de exploração agroextrativa e inviabilizando o desenvolvimento autônomo da região nos ciclos econômicos que se sucederam. Tais processos abriram caminho para as posteriores apropriação generalizada dos recursos e espoliação das comunidades amazônicas, em atendimento às demandas de acumulação do capital extrativo agrário, em um contexto de radicalização do neoliberalismo.

\section{A formação da fronteira extrativa agrária}

Criando um mito da fronteira para dar sentido à história de formação do território norte-americano, Turner (1976) propõe que a conquista territorial representa a formação do novo mundo. A ocupação do Oeste dos Estados Unidos é retratada pelo autor como uma fronteira móvel, uma linha civilizatória que, conforme adentra o território, supera os valores atrasados do velho mundo, forjando os alicerces daquilo que seria uma sociedade libertária, individualista e democrática.

Webb (1979) vai além de Turner (1976), ao propor um mito da fronteira que abarcava não somente os Estados Unidos, mas o conjunto das terras descobertas pelos europeus a partir do século XVI nas Américas, sul da África e Oceania. Juntas, essas representavam cinco ou seis vezes o tamanho da Europa. Webb (1979) unifica esse conjunto de terras como sendo a grande fronteira, que, segundo ele, representava a possibilidade 
de a Europa buscar a solução para os problemas relacionados à escassez de terras, alimentos e demais recursos necessários ao crescimento da população e à melhoria da sua qualidade de vida (WEBB, 1979).

Apesar das críticas e controvérsias, Webb (1979) expressa claramente o que foi a mentalidade do colonizador Europeu quando definiu as terras novas como uma imensa propriedade, que deveria ser explorada para enriquecimento da metrópole. Tal mentalidade se expressará também nas posteriores estratégias de ocupação dos territórios e subjugação dos povos originários (HENNESSY, 1978).

Além do mais, conforme salienta Hennessy (1978), Webb (1979) estabelece uma visão geral do processo de formação do capitalismo no mundo ocidental, assentado na dinâmica extrativa fronteira-metrópole. Tal dinâmica, estabelecida entre a Europa e suas colônias, permitiu, ao longo da história moderna, a formação de um sistema comercial mundial unificado (HENNESSY, 1978), baseado na exploração agroextrativa da fronteira.

É a partir da exploração da chamada grande fronteira que as nações europeias se apropriaram dos recursos necessários para desenvolver as instituições que, com suas inovações nos campos econômicos, sociais e políticos, permitiram a inauguração da modernidade (WEBB, 1979). Por outro lado, é na relação metrópole-colônia que, conforme aponta Becker (2015), se estabelece na América Latina o paradigma da economia de fronteira, marcado pela noção de infinitude de terras e bens naturais a serem colocados à disposição da empresa colonial (BECKER, 2015).

No Brasil, o desenvolvimento capitalista é caracterizado pela formação de um mosaico de economias locais e regionais, a partir de movimentos cíclicos regionalizados marcados pela apropriação territorial itinerante e pela dinâmica da fronteira em movimento. A uma cúpula política mercantil territorial, assentada no controle inabalável da propriedade fundiária, foi possível o desenvolvimento de atividades produtivas itinerantes tais como a agricultura, a extração mineral e a apropriação privada perene do território, tendo à disposição abundantes terras, força de trabalho, recursos naturais, infraestrutura estatal e subsídios públicos (BRANDÃO, 2010). Esse movimento - marcadamente de expansão, exploração e apropriação - e a combinação de atividades caracterizam a fronteira extrativa agrária (SAUER; OLIVEIRA, 2021).

A expansão da fronteira na Amazônia se dá com a implementação de grandes projetos de infraestrutura, a partir da década de 1950, visando à integração nacional. Tal processo ocorre por meio da implementação de rodovias, hidrovias, portos e linhas de transmissão, associada a incentivos e subsídios à exploração agropecuária, mineral e energética. Esse processo de expansão faz vir à tona as reivindicações daquelas populações que, habitando os ditos espaços vazios, veem seus territórios sendo expropriados pelo avanço da fronteira (PORTOGONÇALVES, 2017).

Como não se trata de espaços vazios, Martins (1996) ressalta a natureza de conflito social, que marca a dinâmica de fronteira no Brasil. Conforme o território vai sendo colonizado e transformado pelos diferentes agentes do capital e da modernização, a fronteira se torna o lugar da alteridade (de encontro com o outro), um espaço de encontro de tempos históricos distintos, de diferentes realidades e racionalidades e interesses divergentes quanto ao uso da terra. Na fronteira, tal realidade se expressa fundamentalmente na forma de conflito social, do desencontro entre os diferentes atores sociais, onde a bala do pistoleiro contratado pelo fazendeiro, ao atingir o índio, "[...] atravessa a distância histórica entre seus mundos, que é o que os separa" (MARTINS, 1996, p. 31).

A dinâmica de expansão conflituosa da fronteira extrativa agrária ganha novos impulsos a partir das décadas de 1940 e 1950, que alguns fazem uma analogia com uma "marcha para o oeste" no Brasil (BECKER, 2009a). Segundo Moreira (2011), ação estruturadora do Estado é reforçada no sentido de estabelecer uma divisão territorial do trabalho e das trocas entre a agricultura e a indústria, incentivando a expansão da fronteira para a Amazônia.

Tal arranjo estruturador estatal é realizado acompanhando a forma diversificada com que se dá o processo de acumulação primitiva ${ }^{1}$ nas diferentes regiões do País: avançada no centro-sul, calcada no subsídio à elite cafeicultora e na produção diversificada das colônias de imigrantes; precária no Nordeste, baseada na monopolização de terras, na substituição dos engenhos de cana pela usina no litoral e na articulação da indústria têxtil do algodão com as fazendas de gado no agreste. Na região amazônica, segundo Moreira (2011), a acumulação primitiva é inviabilizada, especialmente dada à forma pulverizada com que se dá a repartição do sobretrabalho do seringueiro ao longo dos elos intermediários da cadeia da borracha, estabelecidos no sistema de aviamento (MOREIRA, 2011).

Inicialmente, os investimentos públicos em termos de infraestrutura logística são realizados no sentido de centralizar o setor de bens de capitais, bens de equipamentos, bens intermediários e bens de consumo durável e a maior parte de bens de consumo não durável, na região centro-sul e, especialmente em São Paulo. 
Posteriormente as indústrias de bens intermediários se redistribuem, localizando-se em polos minero-industriais e energéticos nos limites do arco periférico do espaço brasileiro, que vai do Rio Grande do Sul ao Rio Grande do Norte (MOREIRA, 2011).

Nessa redistribuição, a região centro-sul passa a concentrar os ramos de bens de capital (metalurgia, mecânica, material elétrico, eletrônica e química) e de consumo durável. O Nordeste forma polos de bens intermediários, bens de consumo e agroindústria frutífera que se instalam ao lado das velhas áreas algodoeiro-pastoris e de usinas de açúcar (MOREIRA, 2011), aprofundando o crescimento econômico capitalista desigual (BUNKER, 1988).

A modernização agrícola, com base na revolução verde, a partir da década de 1970, se desloca da região centro-sul, para o centro-oeste (e posteriormente norte do País), subindo do Mato Grosso do Sul para o Planalto Central, aonde chega na forma da pecuária extensiva e das monoculturas alternadas de soja, cana e arroz. A agricultura extensiva e monocultora aliou-se, mais recentemente, à criação de aves e à monocultura de milho (MOREIRA, 2011).

Assim, a agricultura e a indústria se encontram no miolo do espaço nacional e passam a promover um intenso uso tecnológico do solo que é viabilizado por três componentes espaciais: a fronteira em movimento, a exemplo da Plantation $^{2}$; o crescimento demográfico contínuo, que garante a manutenção da força de trabalho necessária à reprodução do binômio monocultura-policultura; e o desenvolvimento do ramo da indústria para a agricultura, que garante a modernização acelerada da produção agrícola (MOREIRA, 2011).

Nesse quadro geral de conformação da nova divisão territorial do trabalho e das trocas entre a agricultura e a indústria e do crescimento econômico desigual, resta à Amazônia o papel de fronteira agrícola, mineral e energética. É um território com uma "posição natural" (especialmente devido à disponibilidade de terras) de zona de expansão das áreas de monoculturas estabelecidas no centro-oeste, especialmente a partir do eixo Belém-Brasília. Tal como ocorria com as áreas de cana e café na faixa da Mata Attântica, a expansão das monoculturas no Cerrado e na Amazônia assume uma dinâmica itinerante, impulsionada pela sucessão desmatamento-arroz-pasto-gado-soja (MOREIRA, 2011), caracterizando não uma industrialização agropecuária, mas uma fronteira com atividades agroextrativas (SAUER; OLIVEIRA, 2021).

A fronteira extrativa agrária é caracterizada pela atuação consorciada da agroindústria mecanizada com os setores mineral e energético, ora viabilizando, ora sendo viabilizada por eles. $\mathrm{O}$ avanço da fronteira extrativa agrária vem favorecendo o aumento do desmatamento e a expropriação dos diferentes grupos sociais que originalmente habitavam o campo, a floresta e as águas. Tal processo vem gerando, por outro lado, a resistência e a mobilização desses grupos sociais no sentido de garantir o seu direito à terra e ao território (MOREIRA, 2011; PORTOGONÇALVES, 2017).

No que se refere à Amazônia, a noção de fronteira deve ser cuidadosamente qualificada, especialmente porque, conforme Bunker (1988), o que se descreve como expansão da fronteira na região envolve, na verdade, o conflito entre sistemas econômicos e institucionais diversos. Longe de assumir um formato linear e progressivo, a expansão capitalista na Amazônia, dada à sua natureza agroextrativa, provoca mudanças localizadas, descontínuas e aleatórias nos sistemas ecológicos e sociais (BUNKER, 1988).

Becker (1986) propõe a interpretação da fronteira amazônica a partir da inserção do Brasil no capitalismo global, em um cenário de profundas mudanças decorrentes de novas tecnologias de produção e gestão e de novas redes de comunicação e circulação. A fronteira torna-se, então, um espaço em incorporação ao espaço global fragmentado, onde é aguçada a contradição entre os interesses gerais e os interesses privados. Ressaltam-se os conflitos entre os diferentes atores que, atuando em diferentes escalas, disputam o território para implementação de projetos políticos distintos (BECKER, 1986; MARTINS, 1996).

\section{Ordem neoliberal e sistema extrativo agrário}

A crise de acumulação do capital, que se inicia na década 1960, se agrava na década de 1970 afetando as principais economias capitalistas, com o aumento descontrolado da inflação e do desemprego. A abolição do ouro como referência material do dólar e a adoção das taxas de câmbio flutuantes e de juros variáveis foram as primeiras medidas no sentido de liberar o fluxo do capital na economia global. A essas medidas seguiu-se uma forte onda de desregulação que possibilitou a expansão dos mercados financeiros e dos investimentos 
externos diretos e indiretos, abrindo caminhos para a apropriação privada dos ativos públicos e dos recursos naturais nos países em desenvolvimento (HARVEY, 2008).

Tais práticas convergiram para a articulação do Consenso de Washington, na década de 1990, que institucionaliza a doutrina neoliberal como o modelo econômico a ser adotado como solução para os problemas globais (HARVEY, 2008). A subordinação do Estado ao mercado, regulado por instâncias supranacionais como o Banco Mundial e o Fundo Monetário Internacional (FMI), torna-se o pilar central do modelo neoliberal.

Nesse contexto, os bens naturais comuns são tratados cada vez mais em termos de mercadorias: produtos primários, de baixo valor agregado, cujos preços são regulados pelas forças de mercado (HARVEY, 2008). Por outro lado, os conflitos com as populações locais, expropriadas pelo processo de privatização e extração dos bens comuns, são encarados em termos de impactos e riscos gerados pelas atividades econômicas, devendo ser minimizados de acordo com a noção de responsabilidade social corporativa (SVAMPA, 2014).

Na América Latina, as diretrizes neoliberais do Consenso de Washington se desdobrarão, nos anos 2000, em um Consenso das Commodities (SVAMPA, 2014). Esse consenso, ou acordo tácito, se relaciona a uma reorientação do mercado global no sentido de reforçar o papel da região como fornecedora de bens primários para as economias mais avançadas (SVAMPA, 2014). Tal processo é favorecido pela emergência da China no cenário econômico mundial e a eleição de governos populares em vários países da América Latina, que aderem ao receituário neoliberal, em nome da estruturação de políticas de transferência de renda, sob o discurso da participação popular e da diminuição das desigualdades sociais (SVAMPA, 2014).

Além ou devido à emergência da China, o aumento da demanda provocou aumento dos preços e um salto no comércio mundial de commodities de U\$1,25 trilhão, em 2004, para mais de U\$4 trilhões, em 2011. Entre 2005 e 2011 as exportações brasileiras para a China cresceram mais de 500\%, saltando de cerca de U\$ 7 bilhões para mais de U\$ 40 bilhões (CASTRO, 2016).

A alta mundial dos preços das commodities ${ }^{3}$ na década de 2000 favorece a consolidação, na América Latina, de um modelo desenvolvimentista baseado na implantação de grandes áreas de monocultivos (especialmente de soja) e na extração intensiva de bens naturais, visando à exportação de bens primários. Destacam-se nesse contexto a extração mineral, a extração de petróleo e gás, a construção de grandes usinas hidrelétricas, a exploração em larga escala de recursos pesqueiros e florestais e a ampliação da fronteira agrícola (mudanças no uso da terra) para a produção de grãos e biocombustíveis. Tal modelo tem como dinâmica a fragmentação territorial e o deslocamento sistemático das populações de seus territórios, causando a explosão de uma série de conflitos socioambientais na região (SVAMPA, 2015).

Ao longo da década de 2000, conforme apontam Sauer e Borras (2016), a narrativa da insegurança alimentar global, impulsionada pelos organismos multilaterais, passa a reforçar um cenário de urgência no investimento em terras, tendo em vista a produção (atual e futura) de alimentos. Desencadeia-se, assim uma dinâmica de apropriação global de terras (land grabbing), especialmente em países como o Brasil, em que há grande disponibilidade de terras férteis e água (SAUER; BORRAS, 2016; SAFRANSKY; WOLFORD, 2011).

A partir da crise financeira de 2008, os temas ou narrativas das crises energética, ambiental e climática (na prática uma combinação de crises globais) se unem ao da crise alimentar, justificando investimentos e impulsionando a apropriação de terras. As narrativas justificadoras são a necessidade de produção de biocombustíveis (para superar a crise energética) e prestação de serviços ambientais (superar a crise ambiental ou climática). Mas a apropriação de terras e bens da natureza não foram apenas para a produção, pois muitos investimentos foram especulativos, ou seja, apropriação de terras como reserva de valor (SAFRANSKY; WOLFORD, 2011).

Diante desse cenário, houve um retorno à lógica extrativa da acumulação primitiva, observada no período colonial (HARVEY, 2003). Orientação para exportação de bens primários, expropriação do espaço das populações locais (indígenas, tradicionais, camponesas), exploração do trabalho análogo ao escravo, supressão das formas alternativas de produção e organização social, avanço contínuo dos monocultivos sobre as áreas de campo/floresta, exaustão de recursos naturais e degradação das áreas exploradas, em um processo denominado por Harvey (2003), não como acumulação primitiva, mas como acumulação por espoliação.

De acordo com Brandão (2010), Harvey procura realçar o conjunto de processos de apropriação que podem ser reunidos sob a denominação de acumulação "primitiva". Esses têm, na verdade, caráter de estratégias permanentes e não circunstanciais no capitalismo, portanto, menos "primitivos" ou precedente, mas parte do sistema capitalista. A usura, a predação, a utilização de artimanhas ilícitas, a apropriação e a expropriação de 
terras e bens naturais, as manobras especulativas, dentre outros, são instrumentos ordinários, sendo práticas regulares em toda a história do capitalismo (BRANDÃO, 2010).

Diante dessa reorientação da economia global, no sentido de recrudescer a lógica da acumulação por espoliação, trabalhos acadêmicos mais recentes (YE et al., 2020) apontam para a disseminação global do extrativismo, enquanto um sistema econômico com características e efeitos específicos. Tal sistema é estruturado sobre a extração exaustiva de um recurso, com grande demanda no mercado global, a um custo mínimo e no período de tempo o mais curto possível (YE et al., 2020).

De acordo com os autores, o extrativismo é caracterizado pela criação de um monopólio sobre os recursos a serem extraídos e depende de um entrelaçamento estreito entre o Estado e o capital privado (YE et al., 2020). $\mathrm{O}$ extrativismo se torna possível pela disponibilidade em termos de infraestrutura requerida (como sistemas de transporte, eletricidade, segurança, força de trabalho etc.) e é viabilizado por um centro operacional que amalgama os diferentes elementos estruturais de extração (no sentido de criar uma cadeia logística que permite que os produtos extraídos sejam transportados dos lugares de pobreza aos lugares de riqueza), transporte e comercialização a preços mais altos (YE et al., 2020).

A riqueza obtida através desse processo extrativo é acumulada no centro operacional pelos grupos de capital envolvidos. De maneira alguma essa riqueza é canalizada para as pessoas afetadas diretamente pelas atividades extrativas, nem para as pessoas ou instituições que poderiam legitimamente reivindicar o seu compartilhamento (YE et al., 2020).

$\mathrm{Na}$ lógica extrativa não existe a preocupação com o investimento na reprodução material dos recursos explorados, atendo-se apenas à extração dos recursos já disponíveis. Toda a riqueza extraída é exportada, ficando no local de extração apenas a degradação do ambiente natural (expropriação), a expropriação da população local (perda de seus bens naturais, expulsão etc.) e o desgaste humano dos trabalhadores envolvidos (exploração). Uma vez exaurido determinado recurso, o extrativismo se desloca para novos domínios e lugares. Tais características fazem do extrativismo um fenômeno destrutivo por natureza (YE et al., 2020).

As corporações extrativas que atuam na extração, transporte e beneficiamento dos produtos primários esperam poder resgatar em algumas décadas o investimento realizado e, para isso, criarão os meios institucionais, políticos e sociais necessários para que não só a extração do produto primário seja realizada, como também o seu beneficiamento e consumo pela sociedade. Isso independentemente de quaisquer constrangimentos advindos da pressão de determinados grupos sociais pela redução dos impactos socioambientais provocados por atividades econômicas dessa natureza (PINEAULT, 2018).

Conforme observado por Pineault (2018) em relação à extração de areia betuminosa no Canadá, o papel do Estado vem sendo fundamental no sentido de favorecer a expansão do capital extrativo agrário, atuando em três frentes principais: liberação de força de trabalho para as regiões de exploração, por meio de intervenções nas políticas de trabalho e emprego; revisão das políticas ambientais, no sentido de facilitar a expansão das atividades de mineração e extração e transporte de óleo e gás; reforço e legitimação da capacidade da indústria extrativa de realizar legalmente a expropriação de comunidades indígenas e municipalidades que venham se opor à expansão espacial da cadeia extrativa, seja no ponto de extração, seja ao longo dos corredores de transporte (PINEAULT, 2018).

A espacialidade da cadeia extrativa é caracterizada pela dinâmica centro-periferia, onde o polo metropolitano é normalmente a cidade portuária, de onde o bem primário será exportado. Tal centro torna-se também lócus privilegiado de coordenação do transporte, comercialização e finanças da produção extrativa. No entorno do polo metropolitano está a fronteira extrativa, por onde se dispersam os diferentes pontos de extração. Os dois são interligados por grandes corredores de transporte que subordinam o território à dinâmica da produção extrativa (PINEAULT, 2018).

É o que observa Porto-Gonçalves (2017) no contexto da implementação de megaprojetos agroextrativos na Amazônia. A reconfiguração territorial imposta pela exploração agroextrativa faz com que as escalas regionais e locais, com suas particularidades socioculturais e territoriais, com seus povos/etnias/nacionalidades, sejam desprivilegiadas nessa lógica de desenvolvimento, tornando-se passagem, fluxos e corredores. Tal modelo inaugura uma nova fase de disputas pelos recursos presentes na terra, na água e no subsolo (PORTO-GONÇALVES, 2017).

\section{Amazônia: fronteira extrativa agrária ${ }^{4}$}


Já na década de 1980, ao analisar a história econômica da Amazônia, Bunker (1988) propunha uma diferenciação entre modo de extração e modo de produção. O autor aponta uma série de características da economia extrativa que permite diferenciá-la dos sistemas produtivos existentes nos países industrializados: o baixo emprego de capital e mão de obra ao valor extraído; a descontinuidade dos padrões de assentamento e do desenvolvimento da infraestrutura; a exploração dos recursos até a exaustão; a dependência tecnológica em relação aos países industrializados; e a estagnação econômica da região explorada, após o término do ciclo extrativa (BUNKER, 1988).

Ao perder energia e matéria, a região extrativa torna-se cada vez mais simplificada, tanto em termos de organização social quanto no que se refere ao ambiente natural, devido à redução do fluxo de energia e à capacidade de retê-la de forma útil. Ao passo que a energia e a matéria que flui aos sistemas produtivos centrais são parcialmente e temporariamente conservadas de forma útil, no sentido de estimular uma organização social cada vez mais complexa e modificações no ambiente físico que promovem uma melhora nas condições de produção (BUNKER,1988).

Bunker $(1984,1988)$ explica o subdesenvolvimento da Amazônia a partir da implementação na região de sucessivos modos de extração que, desde o período colonial, impuseram uma dinâmica de exploração intensa do trabalho e da natureza. Tais modos de extração reduziram a capacidade de regeneração dos ecossistemas e impossibilitaram a organização de uma força de trabalho capaz de responder adequadamente às demandas dos novos mercados criados com o advento da sociedade industrial (BUNKER, 1984).

O colapso da cadeia extrativa da borracha pode ser explicado pelas heranças deixadas pelos ciclos extrativos do período colonial, especialmente no que se refere à dispersão e diminuição da população rural. O próprio regime de trabalho caracterizado pela escravidão por dívida só pôde ser estabelecido graças ao déficit populacional que exigiu o recrutamento de seringueiros de outras regiões, em condições extremamente precárias (BUNKER, 1984, 1988).

Em áreas com baixa densidade populacional os aviadores podiam controlar o suprimento de todos os bens essenciais, com pouca ou nenhuma competição com comunidades agrícolas preestabelecidas. Além disso, como o número de trabalhadores era insuficiente para estabelecer sistemas de plantio da seringueira, a resposta à demanda crescente pela borracha só podia se dar através da exploração de áreas cada vez mais distantes. Tudo isso são fatores fundamentais para explicar tanto os altos custos de extração quanto a concentração da renda ao longo da cadeia extrativa da borracha (BUNKER, 1984).

Bunker (1988) chama atenção para o fato de que a história do boom da borracha teria sido diferente caso se mantivesse o padrão original de ocupação do vale amazônico, com base em uma relação hierárquica entre as áreas de várzea e de terra firme. Os densos e produtivos assentamentos das áreas de confluência dos afluentes com o grande rio poderiam fornecer trabalho e alimentos para as áreas de extração do látex. As consequências demográficas e econômicas, porém, das economias extrativas de exportação tornaram isso impossível. Ao invés disso, as áreas ribeirinhas foram colonizadas por grupos dispersos, contando com economias de subsistência que não se integravam às áreas de terra firme.

O início do século XX é marcado pela consolidação dos limites do território amazônico com a anexação do Acre, em 1903, e o estabelecimento dos limites políticos nacionais concluídos em 1909. Com o fim da República Velha e o estabelecimento do Estado Novo (Governo Vargas 1930-1945), em 1930, inaugura-se o período de consolidação, pela via autoritária, do Estado moderno nacional. A Marcha para o Oeste e a criação da Fundação Brasil Central (1944), a inserção de um Programa de Desenvolvimento para a Amazônia na constituição de 1946 e a criação da Superintendência de Valorização Econômica da Amazônia (SPVEA), em 1953, fazem da Amazônia objeto de planejamento governamental (BECKER, 2009a, 2009b).

Nesse sentido, Bunker (1988), observa que a mediação e a intervenção do Estado, por meio do incremento das capacidades administrativas e o desenvolvimento de um sistema de transporte e comunicação, não levaram a uma incorporação efetiva da Amazônia à nação brasileira. $\mathrm{O}$ despovoamento, os desequilíbrios ambientais e os deslocamentos demográficos e econômicos criados pelos modos de extração anteriores, geraram as condições para que diversos atores, do setor público e privado, passassem a tratar a Amazônia como uma fronteira vazia, de onde os lucros poderiam ser rapidamente extraídos, sem se dar a devida importância aos sistemas econômicos, sociais e ambientais preexistentes (BUNKER, 1988).

Entre 1968 e 1974, é implantada uma malha programada (BECKER, 2009a) sobre o espaço amazônico, tendo em vista a apropriação física e o controle do território pelo Estado. A implantação dessa malha se dá a 
partir das seguintes estratégias: a) implantação de redes de circulação espacial: redes de circulação rodoviária, de telecomunicações, urbanas e hidroelétricas; b) subsídios ao fluxo de capital através de incentivos fiscais e crédito a baixos juros; c) indução de fluxos migratórios para povoamento e formação de um mercado de trabalho regional, inclusive com projetos de colonização; d) superposição de territórios federais sobre os estaduais para facilitar a apropriação de terras dos estados (BECKER, 2009a, 2009b).

A construção das rodovias Transamazônica (ligando a região nordeste ao extremo oeste da Amazônia) e Cuiabá-Santarém se destacam entre as ações promovidas no âmbito do Plano de Integração Nacional (PIN), no sentido de conectar a região amazônica ao resto do país e de viabilizar a circulação de bens e mercadorias. Associada à construção das rodovias estava um projeto de colonização ambicioso a ser levado a cabo pelo recém-criado Instituto Nacional de Colonização e Reforma Agrária (INCRA). Era prevista inicialmente a destinação de dez quilômetros à esquerda e a direita dessas rodovias para implementação da colonização oficial. Em decreto posterior, a largura dessa faixa seria alterada para 100 quilômetros em cada lado das rodovias $^{5}$ (SCHITTINI, 2009).

A produtividade nos assentamentos de colonização, apesar dos bons resultados obtidos durante as primeiras safras, caiu bruscamente em função da falta de financiamento adequado e assistência técnica. Reproduzindo o sistema agrícola de corte e queima, os colonos (migrantes do sul e nordeste) passaram a avançar sobre a floresta com cultivos de subsistência (plantios de mandioca, arroz, milho e feijão). Problemas no desenho dos lotes (que não consideravam adequadamente as características dos ambientes amazônicos), limitações ambientais e ecológicas (que restringiam a viabilidade da agricultura convencional), se somaram às dificuldades de comercialização dos produtos, tornando questionável o modelo de colonização baseado nas agrovilas (SCHITTINI, 2009).

Com a crise do petróleo de 1974, e o subsequente aumento da dívida externa brasileira, ocorre uma nova orientação para a exportação, diante da necessidade urgente de entrada de divisas no país. A colonização oficial torna-se alvo de críticas de políticos e empresários que defendiam uma abordagem mais racional de desenvolvimento, comandada pela iniciativa privada e voltada para fazendas de gado e grandes empreendimentos madeireiros e minerais. Rapidamente os pequenos produtores passaram a ser vistos, pelos órgãos oficiais, como sinônimo de ineficiência, imprudência e degradação ambiental (SCHITTINI, 2009).

Segundo Bunker (1988), a orientação para as grandes empresas foi acentuada pela competição entre madeireiros e pecuaristas, de um lado, e camponeses e pequenos produtores, de outro. A receita e a influência política do INCRA, advindas da taxação e controle patrimonial sobre as terras públicas, gerou uma pressão pela alocação de seus recursos administrativos e financeiros na venda de terras em larga escala e na validação de títulos, ao invés do dispendioso e politicamente sensível processo de colonização e reforma agrária (BUNKER, 1988).

Com a nova crise do petróleo, no final da década de 1970 e início da década 1980, ocorre nova escalada da dívida externa, em função do aumento súbito dos juros no mercado internacional, levando ao esgotamento do modelo de financiamento dos polos de desenvolvimento. Procurando reduzir a despesa pública e aumentar rapidamente as exportações, passa-se orientar o investimento em poucas e grandes áreas selecionadas, ampliandose também a ação militar entendida como necessária à solução dos conflitos. Abre-se caminho então para os grandes projetos mineradores, a exemplo do Programa Grande Carajás ${ }^{6}$ (BECKER, 2009b).

Segundo Becker (2009a), o modelo de ocupação orientado pelo Estado, voltado para a integração da Amazônia à economia do país e baseado nas relações com o mercado internacional, provocou uma reorganização do território amazônico: a construção das rodovias alterou profundamente o padrão da circulação e do povoamento regional. As conexões fluviais (através da calha do Amazonas e seus afluentes) foram substituídas pelas estradas que cortaram os vales dos grandes afluentes e da floresta.

O desmatamento - tanto para a exploração madeireira como para a pecuária — foi associado a intensos conflitos sociais e ambientais, que desfiguraram a floresta nas margens das rodovias a uma largura de, pelo menos, $50 \mathrm{~km}$ de cada lado. Os projetos de colonização, marcados por instabilidade e alto grau de evasão, especialmente dos colonos mais pobres, geraram grande mobilidade intrarregional da população e fraco desempenho econômico (BECKER, 2009a). O povoamento regional passou a ter um padrão concentrado, ao longo das rodovias, separados por grandes extensões florestais. $\mathrm{O}$ adensamento das estradas, na borda da floresta, gerou o grande arco do desmatamento e os focos de calor (BECKER, 2009a).

Ao passar por áreas pouco povoadas no interior da floresta, as rodovias provocaram um novo ciclo de epidemia e violência contra os grupos indígenas que haviam se estabelecido em áreas de terra firme, durante 
os ciclos extrativas anteriores. As rodovias também ameaçaram o assentamento de outras comunidades que combinavam pesca, caça e agricultura de subsistência com o extrativismo de espécies florestais, e que viviam ao longo dos altos cursos dos afluentes do Amazonas (BUNKER, 1984).

Bunker (1984) afirma que esses sistemas rodoviários implantados na Amazônia estimularam o investimento posterior em vias secundárias e vicinais. Apesar dos altos custos desses empreendimentos e de terem contribuído para a renda regional, os benefícios econômicos gerados a longo prazo tornam-se limitados, tendo em vista o caráter predominantemente agroextrativo das atividades econômicas. A exploração madeireira e a pecuária extensiva repetiram os efeitos devastadores no meio ambiente e na população rural dos ciclos extrativos anteriores, agravando o vazio demográfico, que acabou justificando a expansão da fronteira (BUNKER, 1984), caracterizando a fronteira extrativa agrária.

Além da desarticulação dos assentamentos humanos, desperdício de madeira (desmatamento), extinção de espécies e degradação dos solos nas áreas de terra fïme, a formação de pastagem afetou também a produtividade das áreas de várzea a jusante. Os solos erodidos dos pastos, ao serem depositados nos cursos d'água, se acumularam nas áreas de confluência dos rios e causaram inundações, prejudicando cultivos e assentamentos ribeirinhos em áreas de várzea (BUNKER, 1984).

Conforme observado na região de Porto de Trombetas, a extração mineral tem um impacto que vai muito além da área que circunda as minas. $\mathrm{O}$ fluxo de pessoas gerado pela atividade mineradora estimulou a pecuária em larga escala na região e atrelou a economia local à atividade extrativa, em detrimento das atividades agrícolas e florestais (BUNKER, 1984), formando a fronteira extrativa agrária.

O modelo de desenvolvimento induzido pelo Estado - baseado nos subsídios e incentivos a grandes empresas e nos investimentos públicos para a construção das estradas — longe de resgatar a Amazônia dos ciclos de degradação ambiental e fragmentação demográfica dos sucessivos modos de extração, intensificou os efeitos das atividades agroextrativas e não foram capazes de gerar um desenvolvimento autônomo para a região. Desprovida de uma base econômica e social para resistir à expansão predatória do capitalismo, a Amazônia passou a ser controlada pelas corporações, que limitaram a capacidade do Estado de implementar programas voltados à melhoria das condições sociais da população na região (BUNKER, 1988).

O esgotamento do modelo de subsídios estatal para implantação de projetos agropecuários, mineradores e madeireiros é sucedido pela adesão ao receituário neoliberal em meados da década de 1990. Como discutido anteriormente, reforçou o papel do país de fornecedor de commodities ao mercado internacional, especialmente a partir da década de 2000, com a ascensão da China tornando-se o principal parceiro comercial do Brasil. Conforme ressalta BECKER (2015, p. 418), “ [...] não se trata mais de conceder a exploração dos recursos naturais como madeira, minério e solo para empresas transnacionais, mas sim da 'liberação' dos próprios territórios nacionais [...]" que passam a ser controlados pelo grande capital.

Da forma como analisada por Becker (2009b), a competitividade da soja (altos preços e demanda crescente no mercado global), a expectativa de implantação de novos eixos de circulação (infraestrutura de escoamento de grãos e minérios) e uma retomada do valor da terra em um contexto de incerteza econômica mundial irão propiciar novas frentes de expansão do povoamento e da agropecuária em áreas florestais na Amazônia.

A pressão ou demanda crescente por commodities minerais e agrícolas vem provocando um novo ciclo de ocupação colonial na Amazônia por meio da implantação de novas usinas hidrelétricas. É o caso de Belo Monte, no rio Xingu, de Marabá, no rio Tocantins e das usinas do rio Tapajós, todas no Pará. Ou de Teles Pires, na fronteira do Pará com Mato Grosso e de Santo Antônio e Girau, no rio Madeira, em Rondônia. Todas elas tendendo a reproduzir os impactos já observados das grandes barragens na Amazônia: deslocamento de comunidades inteiras, violação de direitos sociais, poluição dos rios, emergência de conflitos, aumento da violência e pobreza no entorno dos empreendimentos, com aumento do desmatamento e reprodução do modelo de exploração agroextrativa, redundando em depressão e estagnação econômica para a região (CASTRO, 2017).

Castro (2017) chama atenção ainda para os investimentos em grandes obras para viabilizar a navegação e o transporte fluvial, com destaque para os terminais portuários. Nesse contexto, grandes rios como o Amazonas, o Tocantins, o Xingu, o Madeira e o Tapajós, com histórico de ocupação milenar, tem seus territórios redefinidos por políticas públicas que buscam atender os interesses dos grupos econômicos do setor mineral, do agronegócio, do papel e celulose e da pecuária (CASTRO, 2017).

Dessa forma, conforme aponta a autora, a Amazônia torna-se uma fronteira internacional de commodities, uma fronteira extrativa agrária, onde são acirradas as estratégias de apropriação de terras e recursos por parte 
de empresas estrangeiras e reforçando os processos de concentração fundiária, grilagem, pistolagem e conflitos em torno da terra, além do desmatamento acumulado (CASTRO, 2017).

\section{Considerações Finais}

A fronteira extrativa agrária é formada no Brasil ao longo do período colonial e avança no sentido de consolidar um modelo de desenvolvimento calcado na concentração de terras, nas desigualdades regionais e na exportação de bens primários. No processo de formação do capitalismo brasileiro, reforça-se o papel da Amazônia como fronteira agrícola, mineral e energética, à medida que o Estado passa orientar o processo de integração da região à estrutura econômica do país.

Com o estabelecimento da ordem neoliberal, acentua-se a lógica extrativa do capital internacional que, diante de uma crise de sobreacumulação, busca ampliar de maneira irrestrita a apropriação privada e a exploração de recursos naturais, ao menor custo possível de extração. Tudo isso visando possibilitar a expansão dos mercados financeiros e dos investimentos externos diretos e indiretos.

A partir de 2010, com o aumento da influência do setor ruralista no governo federal, inicia-se um processo de desregulamentação ambiental e agrária com o objetivo de diminuir as restrições legais ao desmatamento e aumentar a disponibilização de novas áreas ao capital extrativo agrário.

Intensifica-se, assim, o modo de extração na Amazônia, que, gestado no período colonial, promoveu o subdesenvolvimento da região, ao longo dos sucessivos ciclos extrativos. Além de causarem a degradação e a simplificação dos ecossistemas, tais ciclos promoveram rupturas nas diferentes formas de organização social e impossibilitaram a formação de sistemas produtivos que levassem ao desenvolvimento autônomo da região.

\section{Referências}

BECKER, B. K. Geopolítica da Amazônia. In: VIEIRA, I. C. G. (org.). As Amazônias de Bertha K. Becker: ensaios sobre geografia e sociedade na região amazônica: vol. 3. 1. ed. Rio de Janeiro: Garamond, 2015. p. 451-470.

BECKER, B. K. Por que a participação tardia da Amazônia na formação econômica do Brasil? In: ARAÚJO, T. P.; VIANNA, S. T. W.; MACAMBIRA J. 50 anos de formação econômica do Brasil: ensaios sobre a obra clássica de Celso Furtado. Rio de Janeiro, 2009a, p. 471-503.

BECKER, B. K. Amazônia: geopolítica na virada do III Milênio. Rio de Janeiro: Garamond, 2009b.

BECKER, B. K. Signification actuelle de la fronteire: une interpretation géopolitique a partir Du cas de l'Amazonie Brèsilienne. Cahiers des sciences humaines, v. 22, n. 3/4, 1986.

BRANDÃO, C. Acumulação primitiva permanente e desenvolvimento capitalista no Brasil contemporâneo. In: ALMEIDA, A. W. B. et al. Capitalismo globalizado e recursos territoriais: fronteiras de acumulação no Brasil contemporâneo. Rio Janeiro: Lamparina, 2010, p. 39-70.

BUNKER, S. Modes of Extraction, unequal exchange, and the progressive underdevelopment of an extreme periphery: the Brazilian Amazon, 1600-1980. American Journal of Sociology, v. 89, n. 5, p. 1017-1064, 1984.

BUNKER, S. Underdeveloping the Amazon: extraction, unequal exchange and the failure of the modern state. Chicago: University of Chicago Press, 1988.

CASTRO, E. M. R. de. Amazônia na encruzilhada: saque colonial e lutas de resistência. In: CASTRO, E. M. R. de. Territórios em transformação na Amazônia: saberes, rupturas e resistências. Belém: NAEA, 2017. p. 19-48.

CASTRO, J. R. As commodities e seu impacto na economia do Brasil. Nexo Jornal, São Paulo, 31 mar. 2016. Disponível em: https:// www.nexojornal.com.br/explicado/2016/03/31/As-commodities-e-seu-impacto-na-economia-do-Brasil. Acesso em: 27 fev. 2020.

HARVEY, D. O neoliberalismo: história e implicações. São Paulo: Loyola, 2008.

HARVEY, D. O novo imperialismo. 3. ed. São Paulo: Loyola, 2003.

HENNESSY, A. The Frontier in Latin American History. Albuquerque: University of New Mexico, 1978.

MARTINS, J. de S. O tempo da fronteira: retorno à controvérsia sobre o tempo histórico da frente de expansão e da frente pioneira. Tempo Social: Rev. Social USP, São Paulo, n. 1, p. 25-70, 1996.

MOREIRA, R. Sociedade e Espaço Geográfico no Brasil: constituição e problemas de relação. São Paulo: Contexto, 2011.

PEREIRA, L. I. Matopiba: dos ajustes espaciais do agronegócio ao território de esperança do campesinato. Revista NERA, Presidente Prudente, v. 22, n. 47, p. 09-21, 2019. 
PINEAULT, É. The capitalist pressure to extract: the ecological and political economy of extreme oil in Canada. Studies in Political Economy, v. 99, n. 2, p. 130-150, 2018.

PORTO-GONÇALVES, C. W. Amazônia: encruzilhada civilizatória: tensões territoriais em curso. Rio de Janeiro: Consequência, 2017. SAFRANSKY, S.; WOLFORD, W. Contemporary land grabs and their alternatives in the Americas. Prepared for the International Conference on Global Land Grabbing to be held at the Institute for Development Studies, University of Sussex, April 6-8, 2011.

SAUER, S.; BORRAS, J. S. 'Land grabbing' e 'green grabbing': uma leitura da 'corrida na produção acadêmica' sobre a apropriação global de terras. Campo-Território: Revista de Geografia Agrária, v. 11, n. 23, p. 6-42, jul. 2016.

SAUER, S.; OLIVEIRA, K. R. A. Agrarian extractivism in the Brazilian Cerrado. In: McKAY, B. M.; ALONSO-FRADEJAS, A.; EZQUERRO-CAÑETE, A. Agrarian Extractivism in Latin America. New York, Routledge, 2021, p. 64-84.

SCHITTINI, G. de M. Políticas públicas, conservação e movimentos sociais em uma área de expansão de fronteira: a criação de unidades de conservação no âmbito do Plano BR 163 sustentável. 2009. Dissertação (mestrado) - Universidade de Brasília, Centro de Desenvolvimento Sustentável, 2009.

SVAMPA, M. Latin American development: perspectives and debates. Maristella Svampa, Socióloga, escritora e investigadora, Córdoba, 2014. Disponível em: http://maristellasvampa.net/wp-content/uploads/2019/12/Svampa-Latin-American-Development-Perspectivesand-Debates.pdf. Acesso em: 16 maio 2021.

SVAMPA, M. Neoextractivism and enclosure of the commons in Latin America. The South Atlantic Quarterly, v. 114, n. 1, p. 65-82, jan. 2015.

TURNER, F. J. The frontier in american history. New York: Robert E, Krieger Publishing CO, 1976.

VIEIRA, I. C. G.; SANTOS JUNIOR, R. A. de O.; TOLEDO, P. M. de. Dinâmicas Produtivas, transformações no uso da terra e sustentabilidade na Amazônia. In: SIFFERT, N.; CARDOSO, M.; MAGALHÃES, W. de A.; LASTRES, H. M. M. Um olhar territorial para o desenvolvimento: Amazônia. BNDES, 2014. p. 370-395.

WEBB, W. P. The Great Frontier. University of Texas Press, 1979.

WOLFORD, W. The Plantationocene: A Lusotropical contribution to the theory. Annals of the American Association of Geographers. Ithaca, Cornell University, 2021.

YE, J. et al. The incursions of extractivism: moving from dispersed places to global capitalism. The Journal of Peasant Studies, v. 47, n. 1, 155-183, 2020.

\section{Notas}

1 Pereira (2019) enfatiza a definição de acumulação primitiva como sendo o processo de separação do trabalhador do meio de produção, em especial a terra, dando origem ao capitalismo propriamente dito. Conforme ressalta o autor, é um processo que remete ao século XVI, mas que foi recriado posteriormente, "agora não mais com o objetivo de dar a origem ao modo de produção capitalista, mas sim de garantir a sua reprodução e acumulação em outros momentos históricos” (PEREIRA, 2019, p. 9).

2 Plantation é a produção agrícola em larga escala, monocultura, com base no trabalho escravo, no domínio (propriedade privada) da terra e nas lógicas de troca mercantil. Segundo Wolford (2021, p. 2), "A plantation impulsionou a exploração colonial, sustentou uma elite, perpetuou um dualismo centro-periferia dentro e entre os países, organizou uma força de trabalho altamente racializada em todo o mundo e moldou as culturas que consumimos e as normas culturais que habitamos e praticamos", portanto, o mundo vive uma "plantationcene".

3 De acordo com Svampa (2014), o Consenso das Commodities é construído sobre a ideia de que há um acordo — tácito ou explicito - sobre o irrevogável ou irresistível caráter da dinâmica extrativa atual, advinda do crescimento da demanda internacional por produtos primários. Tal consenso serve como uma espécie de barreira que deslegitima a resistência coletiva e cerceia a possibilidade de se pensar em outras noções de desenvolvimento, para além dos projetos extrativistas voltados para a exportação.

4 A opção pelo termo fronteira extrativa agrária, e não apenas fronteira extrativa, possibilita incluir os grandes projetos agropecuários (somados às atividades minerárias e de extração de recursos, como energia, e investimentos em infraestrutura) que vêm impactando a Amazônia, em especial a partir da década de 1960. Por outro lado, é enfatizado o caráter extrativo de tais projetos agropecuários, tendo em vista as características principais da economia extrativa discutidas nesse tópico.

5 O PIN foi criado pelo Decreto Lei ${ }^{\circ} 1.106$, de 16 de junho de 1970 que posteriormente foi alterado pelo Decreto Lei $n^{\circ} 1164$, de $1^{\circ}$ de abril de 1971 (SCHITTINI, 2010).

6 A mineração no âmbito do Programa Grande Carajás foi objeto de uma imensa logística que envolveu, além da instalação da mina de minério de ferro, a construção de ferrovia, porto e da usina hidrelétrica de Tucuruí, alterando toda a face leste do Pará. Nesse processo a Companhia Vale do Rio Doce transforma-se em uma empresa transnacional e se torna a maior acionista dos grandes projetos de mineração implantados no início da década de 1980: Trombetas, Albrás e Alunorte (BECKER, 2009b). 


\section{Gabriel Domingues}

gabrieldominguesea@gmail.com

Mestre em Ecologia pela Universidade Federal de Juiz de Fora (UFJF)

Doutorando no Programa de Pós-Graduação em Desenvolvimento Sustentável (PPGCDS), da Universidade de Brasília (UnB)

\section{Programa de Pós-Graduação em Desenvolvimento Sustentável - PPGCDS/UnB}

Campus Universitário Darcy Ribeiro, Universidade de Brasília (UnB)

Brasília/DF, Brasil

CEP:70910-900

\section{Sérgio Sauer}

sauer@unb.br; sauer.sergio@gmail.com

Doutor em Sociologia (PPG-SOL) pela Universidade de Brasília (UnB)

Professor da Universidade de Brasília (UnB), Faculdade UnB Planaltina, Programa de Pós-Graduação em

Meio Ambiente e Desenvolvimento Rural (PPG-Mader) e PPGCDS

\section{Faculdade UnB Planaltina (FUP/UnB)}

Programa de Pós-Graduação em Meio Ambiente e Desenvolvimento Rural (PPG-Mader)

Área Universitária 01, Vila Nossa Senhora de Fátima

Planaltina/DF, Brasil

CEP: 73345-010

\section{Agradecimentos}

Aos professores Frédéric Mertens (PPGCDS/UnB), Stéphanie Nasuti (PPGCDS/UnB), Marc Lucotte (ISE/UQÀM), Éric Pineault (ISE/UQÀM) e Stéphane Tremblay, pelo apoio e incentivo na realização deste trabalho.

Agência financiadora

Coordenação de Aperfeiçoamento de Pessoal de Nível Superior (CAPES) - Código de financiamento 001. Agosto-Dezembro 2019.

\section{Contribuições dos autores}

$\mathrm{O}$ artigo foi elaborado em todas as partes pelos autores. Aprovação por Comitê de Ética

Não se aplica.

Consentimento para publicação

Consentimento dos autores.

Conflito de interesses

Não há conflito de interesses. 